\title{
DETERMINANTS OF COMPUTER USE IN LOWER SECONDARY SCHOOLS IN JAPAN AND THE UNITED STATES
}

\author{
Albert C. Tuijnman and Alfons C. A. Ten Brummelhuis \\ OCTO, Department of Education, University of Twente, P.O. Box 217, 7500 AE Enschede, \\ The Netherlands
}

(Received 18 March 1991; accepted in revised form 12 February 1992)

\begin{abstract}
The purpose of this study is to investigate the factors explaining differences between schools in the extent to which computers are used by subject teachers as a means of enhancing instruction and optimizing student learning. A conceptual model of key factors in educational reform and innovation is developed on the basis of theory and previous research. The parameters in this model are estimated using the linear structural relations approach and data collected for the International Association for the Evaluation of Educational Achievement (IEA) study of computers in education in two countries, Japan and the United States.

The results show that, in both Japan and the United States, internal innovation assistance, teacher competence and a strategy for monitoring and problem coping are associated with the outcome variable, the degree of computer use in lower secondary schools. In Japan three other variables are also positively related to this outcome: perceptions of the school leadership concerning the relevance of computer use, whether the school has developed an explicit policy for implementation, and whether the school provides opportunities for staff development. Less variation among the predictor variables is found in the United States compared with Japan. The explanation may be that many schools in Japan are still working on the introduction of the innovation, whereas most schools in the United States have reached the stage of institutionalization.
\end{abstract}

\section{INTRODUCTION}

\section{Background}

The great majority of lower secondary schools in the United States have had access to computers for about one decade[1]. By now computers are available in large numbers, as the typical school in the United States can boast a ratio of 17 students to one computer. This position contrasts sharply with that of comparable schools in Japan, where computers were introduced more recently and the student:computer ratio was 143 in the average lower secondary school in 1989[2]. The decision to introduce computers in schools and to use them not only for teaching about computers and their many applications but also as a means of facilitating classroom teaching and learning in traditional subjects was taken much earlier in the United States than in Japan. In $198350 \%$ of the lower secondary schools in the United States used computers already for educational purposes. In Japan this level of computer use was reached in 1987. Accordingly, it can be hypothesized that the typical lower secondary school in the United States has passed through the phases of reform initiation and implementation. Fullan and Stiegelbauer [3] have used the term 'institutionalization' to denote the process of continuation that normally follows on implementation, which refers to what really happens in practice. Whereas schools in the United States may be faced with decisions concerning the continuation and enrichment of existing practices of using computers as a vehicle for instruction, schools in Japan are more likely to be occupied with the development of strategies for coping with implementation problems arising in the introduction of computers in education.

\section{Aims and significance of the study}

The purpose of this study is to measure the factors which, according to theory, can be expected to influence the successful implementation of computers in school education. The second aim is to find out whether and to what extent these antecedent factors correlate among themselves and with the outcome variable, the use of computers for educational purposes. 
The study reported here is significant in at least three respects. Firstly, as noted in the paragraphs that follow, most previous studies have analyzed relationships between only one or a few explanatory factors and the outcome variable, e.g. the application of computers in classroom teaching and learning. This study presents estimates of the correlations existing among a large number of productive factors. The capacity of a given determinant in predicting the outcome can therefore be estimated while the influences of the other antecedent factors are held constant. Secondly, the statistical methods employed make it possible to some extent to separate out the biasing influences of design effects and measurement error. Thirdly, data collected from two rather dissimilar educational systems are studied. The comparative approach can be put to advantage in validating and interpreting the findings.

\section{THEORY AND PREVIOUS RESEARCH}

Theory and experience suggest that the extent to which computers are successfully introduced in schools is enhanced by different situational, financial, organizational and dispositional factors $[1,2,4,5]$. Previous research can tell us a great deal about the factors influencing decisions to initiate major change in education [6-11]. Much is also known about the factors that are associated with the successful implementation of an educational innovation. However, much of this body of knowledge is derived from 'grounded theory' [12], that is, from a logically consistent framework of inductive theories based on data generated mainly by case studies of educational change and innovation. Comparatively little is consequently known about the degree of interaction among the factors determining whether an innovation will be put into practice. Innovation strategies therefore often fail to take sufficiently into account the interrelatedness of the factors that influence actual implementation.

Miles et al.[13] and Fullan and Stiegelbauer[3] discuss a large number of factors which, according to theory and previous research, influence both the decision to initiate educational change and the actual use of the innovation. According to Fullan and Stiegelbauer [3, p. 63] three clusters of factors are associated with the adoption of a decision to initiate and implement a major change in education, for example computer education in schools: relevance, readiness, and resources.

Relevance refers to perceptions of the the usefulness of the innovation. Usefulness can be measured by tapping the expectation of the practitioners the school leadership and teachers that the innovation will produce beneficial outcomes. Fullan and Stiegelbauer quote Firestone [14] as saying that readiness involves the school's "capacity to use reform". Readiness can be approached in terms of variables such as the attitudes to reform of the principal and the prerequisite knowledge and skills of teachers. Resources are closely related to readiness. This factor, which involves the availability of financial means, computer equipment and appropriate software materials, is one of the most frequently studied variables in previous research on aspects of computer education implementation [15].

Over and above these three clusters of variables, which play a role mainly in the initiation process, several key factors in the continuation process can be identified on the basis of theory and research $[3,16]$. Focused on the case of computers in school education, four of the important factors are:

(1) The formulation at school level of explicit policy with respect to the goals, means and ends of computer education,

(2) The organization of staff development, such as the offering of inservice courses for teachers,

(3) The setting up of the monitoring channels and evaluation procedures, and

(4) The organization of technical and expertise support for teachers in need of practical help.

Relationships can be hypothesized among the variables mentioned above. Figure 1 shows a conceptual schema in which the factors which are assumed to play an important role as determinants of the successful implementation of computers in education are specified. The sequence determining the ordering of the variables in this schema is derived from a conceptual framework developed by Pelgrum and Plomp[2], and Tuijnman and Ten Brummelhuis[17]. 


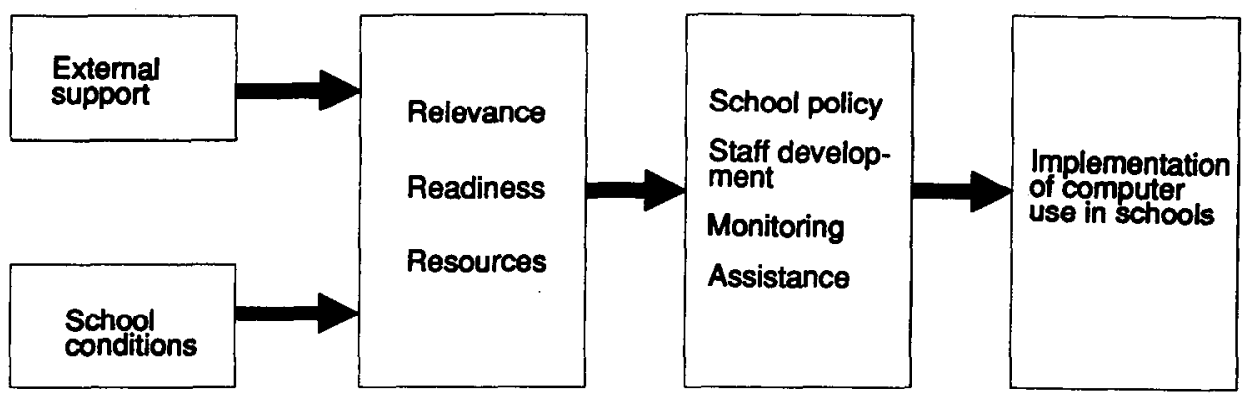

Fig. 1. Key factors influencing the implementation of computer use in schools (adapted from Fullan and Stiegelbauer[3]).

\section{Sample}

All lower secondary schools providing an education for students of the grade in which the modal age was 13 years constituted the target population from which the samples of schools were drawn. For obvious reasons, the data sets examined in this article had to be restricted to schools actually using computers for instructional purposes. In all, a total of 230 Japanese schools were examined, compared with 305 schools in the United States.

The original data were collected by the International Association for the Evaluation of Educational Achievement (IEA) national research centres in 21 countries in a survey carried out early in 1989. The survey covers primary, lower secondary and upper secondary schools not using computers as well as those that do. Within the sampled schools, questionnaires directed at school principals, school computer coordinators and teachers. For the analyses reported here only school level data from two educational systems were used.

\section{Variables}

The information used to measure the variables employed in this study was taken from the questionnaires to which the principals and resource persons acting as computer coordinators in the schools had responded. Information collected from the teachers was aggregated to school level in order to measure two of the theoretical or latent variables mentioned in Table 1, namely 'readiness' (self-assessed competence of teachers) and 'assistance' (provision of internal resource assistance). The mean scores, standard deviations and reliabilities of these two as well as the other latent variables used in this study are shown in Table 1 . The items associated with the theoretical variables are described in the Appendix.

The dependent variable, instructional use of computers in schools, warrants special consideration. This variable has five categories with rank scale scores from 4 to 0 . It is based on the use of computers in grade 8 in four subjects, namely computer education, mother tongue, mathematics and science. A score value of 2 , for example, indicates that in grade 8 in a given school computers are used for instruction in two of the four subject areas. The information used in measuring this criterion is provided by the principals and computer coordinators.

Table 1. Description and summary statistics of theoretical variables ( $N$ items, $\bar{X}$ mean score, SD standard deviation, $R$ reliability)

\begin{tabular}{|c|c|c|c|c|c|c|c|c|c|}
\hline \multirow{2}{*}{\multicolumn{2}{|c|}{ Theoretical variables }} & \multicolumn{4}{|c|}{ Japan } & \multicolumn{4}{|c|}{ United States } \\
\hline & & \multirow{2}{*}{$\frac{N_{i}}{1}$} & \multirow{2}{*}{$\frac{\bar{X}}{3.00}$} & \multirow{2}{*}{$\frac{\mathrm{SD}}{1.12}$} & \multirow{2}{*}{$\frac{R}{0.85}$} & \multirow{2}{*}{$\frac{N_{i}}{1}$} & \multirow{2}{*}{$\frac{\not \bar{X}}{2.03}$} & \multirow{2}{*}{$\frac{S D}{0.80}$} & \multirow{2}{*}{$\frac{R}{0.85}$} \\
\hline$x_{1}$ & School size & & & & & & & & \\
\hline$X_{2}$ & External financial support & 1 & 0.57 & 1.13 & 0.85 & 1 & 1.84 & 1.62 & 0.85 \\
\hline$X_{3}$ & External training support & & & & NA & 12 & 2.23 & 1.11 & 0.66 \\
\hline$X_{4}$ & Previously innovation experience & 1 & 2.85 & 1.48 & 0.95 & 1 & 4.72 & 2.21 & 0.85 \\
\hline$x_{5}$ & Availability and resource needs & 3 & 3.10 & 1.10 & 0.74 & 3 & 3.06 & 1.04 & 0.61 \\
\hline$x_{6}$ & Perceived innovation relevance & 3 & 2.17 & 0.75 & 0.69 & 3 & 2.27 & 0.73 & 0.80 \\
\hline$X_{7}$ & School policy for computer use & 3 & 0.84 & 1.56 & 0.82 & 3 & 0.48 & 0.81 & 0.78 \\
\hline$X_{8}$ & Internal staff development & 3 & 1.42 & 1.68 & 0.62 & 3 & 0.53 & 1.29 & 0.76 \\
\hline$X_{9}$ & Internal innovation assistance & 3 & 1.81 & 1.01 & 0.88 & 3 & 1.72 & 1.05 & 0.75 \\
\hline $\boldsymbol{x}_{10}$ & Teacher competence and readiness & 22 & 16.4 & 5.01 & 0.93 & 22 & 15.2 & 5.53 & 0.94 \\
\hline $\boldsymbol{X}_{11}$ & Monitoring and problem coping strategy & 2 & 2.75 & 1.04 & 0.70 & 2 & 2.50 & 0.87 & 0.64 \\
\hline$Y_{1}$ & Implementation of computer use & 1 & 1.37 & 1.03 & 0.85 & 1 & 2.39 & 1.13 & 0.85 \\
\hline
\end{tabular}


Figure 2 shows the number of schools with computers as a percentage of all lower secondary schools in Japan and the United States. The percentage of schools using computers for instruction in one, two, three or four subjects in grade 8 is also indicated. It can be seen that $56 \%$ of the Japanese schools did not use computers in any of the four subject areas in 1989. By comparison, nearly all lower secondary schools in the United States made use of computers at that time. The area on the right-hand side of the curve indicates the degree of implementation. It can be seen that the United States' school system has advanced more than twice as far as Japan on the path to full implementation.

\section{Statistical approach}

In the strategy used to obtain the theoretical or latent variables, the first step was to find out if the theoretical variables could be appropriately identified using similar items measured on the same scale. To this end the distributions and standard deviations of all possible indicators were examined across at least six of the countries participating in the IEA study of computers in education. The number of items available for comparative analysis was reduced, since observed variables lacking in variance or suffering from other deficiencies of measurement were excluded. An attempt to improve the distributions of highly skewed variables was made early in the study, by applying transformation procedures. The aim was to achieve as closely as possible a normal distribution of scores across categories. The method of principal components analysis was then used to select and exclude manifest variables with confounded measurements.

A second step involved the computation of so-called optimal correlations among the observed variables. Polychoric and polyserial correlation coefficients for ordinal, censored and continuous variables were computed using a preprocessor to the LISREL computer program[18]. One advantage of this procedure is that data involving sets of ordered categories can be handled and, hence, that bias in correlations involving dichotomous and ordinal variables can be substantially reduced. In this study, scores on such variables were transformed to normal scores determined from



Fig. 2. Degree of implementation of computer education in four subjects in lower secondary schools in Japan and the United States (percentage schools with computers and percentage schools using computers in four subjects). 
the marginal distributions and optimal correlations between variables measured on different scale types were computed. Tests of bivariate normal distributions were carried out in order to check whether this approach was in fact admissible. Simple product-moment correlations were employed in instances where the test had failed.

Thirdly, the LISREL (linear structural relations analysis) approach and the maximum likelihood method were used in this study in order to estimate the reliabilities of observed and theoretical variables. (After squaring, the factor loading of an item associated with a given theoretical variable can be interpreted as a lower bound estimate of the reliability of the item in measuring the latent variable.) As can be seen from the reliability estimates presented in Table 1, most variables are measured with substantial error. It is common in social science research to "overlook" the consequences of error variance - even though it is generally known that the data are mostly imperfect. The LISREL approach used in this study presents a means for modeling and estimating measurement error and taking error into account in statistical analyses of relationships. A useful summary of the theories guiding the application of LISREL can be found in Jöreskog and Sörbom [19].

\section{Estimation and control of measurement error}

If many observed variables are available as indicators of an underlying construct, then the reliability of the items and the associated latent variable can be estimated using item and scale analysis procedures. This was done in the case of the variable 'teacher competence and readiness'. The reliability coefficient thus obtained was built into the measurement model at a later stage in the analysis of data.

The reliability of a single observed item cannot easily be determined once the data have been collected. Yet it can often be inferred from the residual variances in covariance structure models that variables such as 'school size' and 'previous innovation experience' are beset with measurement problems. A decision was therefore taken to assign standard error variances of 0.15 to the two variables in question.

The reliabilities of all the other observed and theoretical variables employed in this study were estimated directly in a so-called confirmatory analysis of covariance structures. The purpose of this analysis was not only to establish how well the measures served as indicators of their underlying theoretical variables but also to estimate the correlations among the theoretical variables while holding residual error variance constant. The resultant "true" correlations, which are referred to as 'disattenuated' coefficients, can be considered optimal because the biasing influences of the sum of random error components (e.g. item specific error, design and sampling error and response error) are 'partialled out' of the correlation coefficients.

It is important especially in investigations such as the present one, which involves highly theoretical abstractions such as 'teacher readiness' and 'innovation relevance', to produce true score variances by controlling for the possibly biasing influences of specific and random measurement error. Accordingly, the results presented below may well be of substantive interest for theoretical as well as statistical reasons. A word may be needed concerning the interpretation of the disattenuated coefficients. In examining simple product moment correlations it is common to disregard coefficients with values less than 0.35. A lower value can be used for judging the significance of disattenuated coefficients estimated in a LISREL measurement model. In this article a threshold value of 0.20 is used.

\section{RESULTS}

\section{Associations among productive factors in Japanese schools}

Table 2 presents a matrix of disattenuated correlations estimated among the factors influencing the implementation of computer education in Japanese schools. For reasons obvious to the reader, these coefficients cannot and should not be interpreted in casual terms. However, they provide us with an indication of the degree of interrelatedness among these 'productive' factors and their degree of association with the outcome variable: the pervasiveness of computer use in lower secondary education. 
Table 2. Matrix of dissattenuated correlation coefficients, Japan. $N=230$

\begin{tabular}{|c|c|c|c|c|c|c|c|c|c|c|c|}
\hline 1. School size & $\begin{array}{l}1 \\
1.00\end{array}$ & 2 & 3 & 4 & 5 & 6 & 7 & 8 & 9 & 10 & 11 \\
\hline 2. External financial support & -0.23 & 1.00 & & & & & & & & & \\
\hline 3. Previous innovation experience & 0.15 & -0.07 & 1.00 & & & & & & & & \\
\hline 4. Availability and resource needs & 0.05 & 0.02 & -0.28 & 1.00 & & & & & & & \\
\hline 5. Perceived innovation relevance & -0.19 & 0.22 & 0.14 & 0.08 & 1.00 & & & & & & \\
\hline 6. School policy for computer use & -0.21 & 0.08 & 0.10 & -0.25 & 0.24 & 1.00 & & & & & \\
\hline 7. Internal staff development & -0.17 & 0.17 & 0.06 & -0.13 & 0.30 & 0.38 & 1.00 & & & & \\
\hline 8. Internal innovation assistance & -0.07 & 0.15 & 0.14 & -0.19 & 0.28 & 0.23 & 0.40 & 1.00 & & & \\
\hline 9. Teacher competence and readiness & -0.03 & 0.02 & 0.06 & -0.25 & 0.16 & 0.11 & 0.28 & 0.31 & 1.00 & & \\
\hline 10. Monitoring and problem coping strategy & -0.13 & 0.11 & 0.27 & -0.15 & 0.33 & 0.40 & 0.48 & 0.27 & 0.26 & 1.00 & \\
\hline 11. Implementation of computer use & -0.19 & 0.21 & 0.05 & -0.25 & 0.26 & 0.40 & 0.43 & 0.34 & 0.33 & 0.55 & 1.00 \\
\hline
\end{tabular}

It can be seen from the values recorded in Table 2 that external financial support and school size are negatively related, while positive associations are found between financial support on the one hand and perceptions of innovation relevance and the outcome, use of computers. School size seems to be mainly negatively associated with the other factors. The number of years schools have had access to computers seems to play an important role in the strategy schools have devised for monitoring and problem coping. As can be expected innovation experience is negatively related to resource needs in terms of the supply of hardware and software. Perceptions of innovation relevance seem to be associated with the willingness of leadership to formulate explicit school policy, to organize staff development and internal support activities and to devise for monitoring computer use and active implementation.

In line with expectation is the finding that availability (or, rather, non-availability, as the items measure the urgency of the need for additional equipment and resources) is consistently (and negatively, as can be expected in this case) related to both antecedent and outcome variables. This means that a shortage of either hardware or software, or both, is a real and important limiting factor in implementation. This replicates the results arrived at in other investigations on aspects of computer implementation, cf. Klein et al. [15].

The data provide a clear indication that a school policy for computer implementation is linked up with the school-based provision of staff development activities and internal innovation assistance. Substantial correlations are also found between school policy and the dependent variable. Only about one-third of the schools in Japan had formulated an explicit school policy in 1989. Yet the schools which did have policy had a much higher probability of being ahead of others in implementing computers in education than schools lacking written policy. It can be hypothesized that an effective means of speeding up the process of implementing computers in the Japanese school system may be to require all the schools to develop policy. The last five variables in Table 2, i.e. staff development, innovation assistance, teacher competence and readiness, monitoring and implementation, generally show high intercorrelations. In the case of Japan, school policy, staff development and information exchange as strategy for monitoring and problem coping are factors tied to the implementation process.

\section{Associations among productive factors in U.S. schools}

It can be inferred from the estimates recorded in Table 3 that school size shows significant correlations with teacher competence and monitoring as well as with the dependent variable, computer use in schools. In the United States, apparently, the bigger the school the higher the chance that students use computers during lessons. Whereas external financial support and training support are interrelated, the latter seems to have more impact than the former, especially with respect to monitoring.

Previous innovation experience seems only to have impact on teacher competence and readiness but the latter has subsequently an impact on the actual use of computers in schools. Relevance and monitoring have also something in common. An interesting finding is the negative correlation between resource need or non-availability and innovation monitoring and problem coping strategy. It seems that schools with lack of resources have less information exchange about computer use than other schools. That school policy and staff development correlate is in accordance with expectation, as the latter may be considered to form part of an active policy. The availability of 
Table 3. Matrix of disattenuated correlation coefficients, U.S.A. $N=305$

\begin{tabular}{|c|c|c|c|c|c|c|c|c|c|c|c|c|}
\hline & 1 & 2 & 3 & 4 & 5 & 6 & 7 & 8 & 9 & 10 & 11 & 12 \\
\hline 1. School size & 1.00 & & & & & & & & & & & \\
\hline 2. External financial support & 0.10 & 1.00 & & & & & & & & & & \\
\hline 3. External training support & 0.11 & 0.30 & 1.00 & & & & & & & & & \\
\hline 4. Previous innovation experience & 0.17 & 0.05 & 0.07 & 1.00 & & & & & & & & \\
\hline 5. Availability and resource needs & -0.12 & -0.10 & -0.25 & -0.14 & 1.00 & & & & & & & \\
\hline 6. Perceived innovation relevance & 0.05 & -0.10 & 0.18 & -0.15 & -0.11 & 1.00 & & & & & & \\
\hline 7. School policy for computer use & -0.02 & -0.08 & -0.01 & -0.09 & -0.06 & 0.06 & 1.00 & & & & & \\
\hline 8. Internal staff development & 0.00 & -0.01 & 0.05 & 0.02 & -0.09 & 0.07 & 0.22 & 1.00 & & & & \\
\hline 9. Internal innovation assistance & 0.16 & 0.05 & 0.07 & 0.05 & 0.10 & 0.14 & 0.04 & 0.17 & 1.00 & & & \\
\hline 10. Teacher competence and readiness & 0.40 & -0.01 & 0.10 & 0.25 & -0.19 & -0.06 & 0.09 & 0.03 & 0.16 & 1.00 & & \\
\hline 11. Monitoring and problem coping strategy & 0.21 & 0.06 & 0.24 & 0.20 & -0.44 & 0.26 & 0.18 & 0.19 & 0.12 & 0.22 & 1.00 & \\
\hline 12. Implementation of computer use & 0.34 & 0.12 & 0.06 & 0.01 & 0.10 & 0.02 & 0.02 & 0.01 & 0.25 & 0.20 & 0.20 & 1.00 \\
\hline
\end{tabular}

internal innovation assistence correlates with computer use, and teacher competence is associated with monitoring as well as with the outcome, computer use in schools.

\section{Structural parameters}

The disattenuated coefficients reported in the previous sections were used as a basis for estimating a structural LISREL model of factors influencing the outcome variable. The phenomenon of implementing computers in schools is specified in this model in terms of putative cause-and-effect variables. As Jöreskog and Sörbom [18, p. 1] observe:

"Because the equation represents a causal link rather than a mere empirical association, the structural parameters do not, in general, coincide with coefficients of regressions among observed variables. Instead, the structural parameters represent relatively unmixed, invariant and autonomous features of the mechanism under study".

It is normal to use unstandardized estimates in comparing coefficients of regression based on data obtained from different samples. However, in the present study the latent variables were standardized. This seems justified because, as the above quotation shows, LISREL parameters can be considered 'unmixed' and 'autonomous'. Another justification is that disattenuated coefficients based on similar items were used as input into model building.

\section{Antecedents of computer implementation in schools}

Table 4 presents the results. It can be inferred from the $t$-values, which show the level of statistical significance associated with the parameters, that six factors seem to have an impact on computer implementation in the case of Japan. It may be worth repeating that these effects are estimated while other variances, including the error variances, are held constant in the model. The following theoretical variables show a significant direct effect: external financial support $(0.11)$, school policy $(0.13)$, teacher competence $(0.13)$ and monitoring and problem coping strategy $(0.40)$. Collectively, these factors account for $44 \%$ of the variance in the dependent variable.

Table 4. Determinants of computer implementation in lower secondary schools (standardized regression coefficient and $t$-value of coefficient)

\begin{tabular}{lrrrrr}
\hline & \multicolumn{2}{c}{ Japan } & & U.S.A. \\
\cline { 2 - 3 } \cline { 5 - 6 } Independent variables & \multicolumn{1}{c}{$\boldsymbol{B}$} & $\boldsymbol{t}$-value & \multicolumn{1}{c}{$\boldsymbol{B}$} & $\boldsymbol{t}$-value \\
\hline 1. School size & -0.037 & -0.679 & & 0.271 & 4.610 \\
2. External financial support & 0.112 & 2.080 & & 0.080 & 1.421 \\
3. External training support & & & & -0.037 & -0.630 \\
4. Previous innovation experience & -0.118 & -2.093 & & -0.125 & -2.200 \\
5. Availability and resource needs & -0.131 & -2.337 & & -0.044 & -0.721 \\
6. Perceived innovation relevance & 0.001 & 0.018 & & -0.062 & -1.064 \\
7. School policy for computer use & 0.129 & 2.137 & & -0.007 & -0.126 \\
8. Internal staff development & 0.083 & 1.317 & -0.047 & -0.855 \\
9. Internal innovation assistance & 0.088 & 1.485 & & 0.207 & 3.700 \\
10. Teacher competence and readiness & 0.133 & 2.362 & & 0.053 & 0.874 \\
11. Monitoring and problem coping stretegy & 0.395 & 6.168 & & 0.143 & 2.214 \\
Explained variance & 0.436 & 10.464 & & 0.159 & 12.104 \\
Number oaf cases & 230 & & & 305 & \\
\hline
\end{tabular}

Dependent variable: implementation of computer use. 
In the case of the United States three antecedent factors seem to have statistically significant effects on the outcome variable: school size $(0.27)$ internal innovation assistance $(0.21)$ and problem coping stretegy (0.14). Collectively, these factors account for $19 \%$ of the variance in the dependent variable.

\section{DISCUSSION}

In examining and comparing the disattenuated coefficients estimated on the basis of the data collected from schools in Japan and the United States, the first impression is that the degree of association among the factors in the U.S. data set is generally low. Given the comparatively large number of available computers in lower secondary schools in the United States, and also given the fact that this country was among the first in the world to initiate educational reform involving the introduction of computers in school education, it can be hypothesized that the United States should be well ahead of Japan in terms of implementation and actual use of computers in instruction. So why do the results - interpreted in terms of the variance explained in the dependent variable--seem to contradict this? A plausible explanation could be that the factors specified in the structural model are focused on accounting for reform initiation and the early phases of implementation. This assertion is in line with generic theories of educational reform evaluation, such as the one developed by Fullan and Stiegelbauer[3].

An educational system such as the one of Japan, where computers were introduced quite recently compared with the United States, shows much more variation in the variables predicting reform initiation and implementation. In the United States, on the other hand, where most schools have had a decade of experience with computers in education, less variation is found among the key factors used in the present investigation.

In the United States it seems that most schools with respect to computer use have reached the stage of institutionalization[20]. This may explain why there is less variation among the antecedent variables. A cautionary note may be appropriate here. It must be recalled that the dependent variable is based on the use of computers in the subject areas math, science, mother tongue and computer education and does not measure how much instruction about and with computers the students actually receive. Hence the results cannot be interpreted as suggesting that the Japanese students receive more instruction with computers than students in the United States. That the parameters in the United States model show less fit with theory than the Japanese data may be a consequence of substantially less variation and covariation among the variables.

\section{CONCLUSION}

Even though a confirmatory factor analytic procedure was employed in this study in estimating the structural relationships among the productive factors, the findings must nevertheless be considered tentative. There are several reasons for this. Firstly, the dependent variable in the model, computer implementation, was measured at the between-school and not the between-classroom level. This will be one of the aims of the second stage of the IEA computers in education study. Secondly, the model was fitted to data collected in only two educational systems. It may be of interest to test the hypotheses guiding the specification of variables in the model against data collected in additional systems. Such an elaboration would not only offer a means of examining the validity of the model and provide a context for interpreting the findings, but would also make it possible to test empirically the central hypothesis guiding the design of this comparative study, namely, that there are certain distinctive developmental stages through which all systems seeking to implement computers in schools proceed. Finally, it would be of great interest if the relationships of the productive antecedent factors in the U.S. and Japanese models, on the one hand, and measures of classroom practice and student achievement on the other, could be estimated. This information is indispensable, as it may well provide decision-makers and school personnel with the practical knowledge they require in order to improve the quality and effectiveness of computer use in education. The collection of such data is the aim of the second, longitudinal phase of the IEA Computers in Education Study. 
Acknowledgements - The data employed in this article are derived from the IEA Computers in Education study. We wish to thank IEA and its International Coordinating Center at the Department of Education, University of Twente, for making the data available to us. We are very grateful to Arjan Schipper for helping with the data processing.

\section{REFERENCES}

1. Becker H. J., School Uses of Microcomputers. Reports of a National Survey. Johns Hopkins University Press, Baltimore, Md (1983).

2. Pelgrum W. J. and Plomp Tj. The Use of Computers in Education Wordwide. Pergamon Press, Oxford (1991).

3. Fullan M. G. and Stiegelbauer S., The New Meaning of Educational Change. Cassell, London (1991).

4. Kulik J. A., Bangert R. L. and Williams G. W., Rev. Educ. Res. 50, 525 (1983).

5. Akker J. van den, Keursten P. and Plomp Tj. Int. J. Educ. Res. 17, 65 (1992).

6. Huberman M. and Miles M. B., Innovation Up Clopse. Plenum Press, New York (1984).

7. Fullan M. G. The Meaning of Educational Change. Teachers College Press, New York (1982).

8. Fullan M. G., Curriculum implementation. In The International Encyclopedia of Education (Edited by Husén $T$. and Postlethwaite T. N.), pp. 1208-1215. Pergamon Press, Oxford (1985).

9. Fullan M. G., Miles B. M. and Anderson S. E., Strategies for Implementing Microcomputers in Schools: The Ontario Case. Queens Printer, Toronto (1988).

10. Velzen W. G. van, Miles B. M., Ekholm M., Hameyer U. and Robin D., Making School Improvement Work: A Conceptual Guide to Practice. ACCO Leuven (1985).

11. Creemers B. P. M. and Scheerens J., Int. J. Educ. Res. 13, 685 (1989)

12. Glaser B. G. and Strauss A. L., The Discovery of Grounded Theory: Strategies for Qualitative Research. Wiedenfeld \& Nicolson, London (1968).

13. Miles B. M., Saxi E. and Lieberman A., Curriculum Inquiry 18, 157 (1988).

14. Firestone W., Educ. Eval. and Policy Analysis 11, 151 (1989).

15. Klein L. A., Cerullo M. J. and Cerullo M. V., Computers Educ. 16, 257 (1991).

16. Louis K. and Miles M. B., Improving the Urban High School: What Works and Why. Teachers College Press, New York (1990).

17. Tuijnman A. C. and Ten Brummelhuis A. C. A., Measuring and predicting computer education implementation in Dutch and United States schools: a structural model. In The Use of Computers in Education Worldwide (Edited by W. J. Pelgrum and Tj. Plomp), pp. 155-171. Pergamon Press, Oxford (1991).

18. Jöreskog K. G. and Sörbom D., LISREL 7. A Guide to the Program and Applications, 2nd edn. SPSS International B.V., Gorinchem, The Netherlands (1988).

19. Jöreskog K. G. and Sörbom D., Linear structural relations analysis. In The International Encyclopedia of Education, Supplementary Volume II (Edited by Husén T. and Postlethwaite T. N.), pp. 368-376. Pergamon Press, Oxford (1990).

20. Becker H. J., Computer use in the United States schools: 1989. Paper presented at the 1990 meetings of the American Educational Research Association (1990).

\section{APPENDIX \\ Description of Theoretical and Observed Variables}

(1) School size

This variable is based on the number of students enrolled in school. The data are recorded into three categories: small, medium and large schools.

(2) External financial support

One item is used as indicator for the provision of financial support by the government.

(3) External training support

Twelve items are employed. These measure support received from (a) computer manufacturers, (b) software producers and (c) other businesses in each of the four areas mentioned previously. Many items in the Japanese data set showed zero variance, often indicating that no support was reccived by the school. Business support could therefore not be retained for further analysis.

(4) Previous innovation experience

One item is available. it is derived from the year in which computers were first introduced in the school. The variable thus measures the number of years of experience schools have had with computers in education.

(5) Availability and resource need

Four items measuring the urgency of the need for additional hardware and software are used as indicators of availability and resource need on the assumption that schools well supplied with, for example, computer hardware, will assign a low priority to the purchase of new such equipment. The four items used in the analysis are: (a) need for more powerful computers, (b) need for network for shared disk storage, (c) need for more tool software (Japan only) and (d) need for greater variety of instructional software (US only).

(6) Perceived innovation relevance

This variable is based on four items. These tap the expectations of the principle that computers will (a) increase productivity, (b) make teaching more effective (US only), (c) enhance student creativity (Japan only), (d) increase student achievement.

(7) School policy for computer use

Four items are employed in the analysis. These measure whether the school has written down policy statements with respect to the means and ends of computer education, e.g. (a) all students should have to acquired some experience with computers before their graduation, (b) instruction with computers must be compulsory, (c) the school shall give priority to the use of computers for instruction (US only), and (d) the school prescribes which hardware and software should be used by teachers and students (Japan only). 


\section{(8) Internal staff development}

Three items are employed. These measure whether the teachers can attend (a) an introductory course on how to use computers, (b) a course on the use of application programs, and (c) a course on how to use computers for teaching in specific subjects.

(9) Internal innovation assistance

A sample of subject teachers in schools were asked whether internal support was available at school level to solve problems arising from (a) the use of hardware, (b) the use of software, (c) the use of computers in instruction (Japan only), and (d) the organization of the teaching and learning process (US only). This information, which gives an indication of the support and assistance available to teachers who use computers for instruction, is aggregated to school level.

(10) Teacher competence and readiness

Subject teachers were sampled for the subject matter areas computer education, mother tongue, math and science in each sampled school with computer use. The teachers were asked to indicate by checking 'yes' or 'no' whether they had the knowledge or could perform the task mentioned in three groups of statements: (a) knowledge of computers and applications [I know ..., 9 items], (b) the ability to write or adapt software [I can write a program for .., 5 items], and (c) the capacity to actually use computers as an aid in instruction [I am capable of . .,8 items]. A total score was computed per teacher and the teacher with the highest score was selected to represent the school. The score of the selected teacher indicates the highest knowledge and skill level available at school.

(11) Monitoring and problem coping strategy

Two items indicating whether monitoring procedures exist in the school are employed in the analysis. These are based on responses to questions asking whether the school exchanges information and experience on how computers are and can be used as an aid in teaching.

(12) Implementation of computers use

This variable is measured on a five point scale and is based on the use of computers in grade 8 in the following four subjects: computer education, mother tongue, mathematics and science. Each rank scale score indicates the number of subjects with computer use in grade 8. 